\title{
Increased mortality in hip fracture patients living alone. A NOREPOS study
}

Cecilie Dahl ${ }^{1}$, Ph.D., Kristin Holvik ${ }^{2}$,Ph.D, Haakon E. Meyer ${ }^{1,2}$,Ph.D, MD, Hein Stigum ${ }^{1,2}$,Ph.D, Siri M. Solbakken ${ }^{1}$, Ph.D., MD, Berit Schei ${ }^{3,4}$, Ph.D., MD, Anne-Johanne Søgaard ${ }^{2}$, Ph.D., Tone Kristin Omsland ${ }^{1}$, Ph.D.

Affiliations:

1. University of Oslo, Institute of Health and Society

2. Norwegian Institute of Public Health, Department of Chronic Diseases and Ageing

3. Norwegian University of Science and Technology, Institute of Community Medicine and Nursing

4. Department of Obstetrics and Gynecology St. Olavs Hospital, N-7006 Trondheim, Norway

Corresponding author: Cecilie Dahl, Institute of Health and society, Box 1130

Blindern, 0318 Oslo, Norway Email: cecilie.dahl@medisin.uio.no, phone: +47 22850630

Short title: Living situation and post-hip fracture mortality

Supplementary data: Methods clarification and 6 extra tables included

Disclosures: All authors state no conflict of interest 


\section{Abstract}

Hip fracture is associated with excess mortality, persisting for many years after the fracture. Several factors may affect survival; however, the role of social support has been less studied. Living situation could be an indicator of a person's social support, which predicts mortality in the general population. In this longitudinal cohort study, we considered whether living alone was a risk factor for post-hip fracture mortality compared to living with a partner.

Information on hip fractures from all hospitals in Norway 2002-2013 was combined with the 2001 National Population and Housing Census. The association between living situation and mortality during 12.8 years of follow-up in 12,770 men and 22,067 women aged $50-79$ years at fracture was investigated using flexible parametric survival analysis. We also estimated relative survival of hip fracture patients compared to that of the non-fractured background population in the same living situation (alone or with a partner).

Higher mortality after hip fracture was found in both men and women living alone versus with a partner: hazard ratio $(\mathrm{HR})$ men=1.37, 95\% confidence interval $(\mathrm{Cl}): 1.29,1.44$, $\mathrm{HR}$ women $=1.23,95 \% \mathrm{Cl}: 1.18$, 1.28 , adjusting for age, education level, urbanization degree and number of children. We demonstrated the strongest association in male hip fracture patients $<60$ years of age (long-term mortality HR=3.29, $95 \% \mathrm{Cl}: 2.25,6.49)$. Compared to the general population, relative survival 8 years after a hip fracture was $43 \%$ in men and $61 \%$ in women living alone, whereas relative survival in those living with a partner was $51 \%$ in men and $67 \%$ in women.

In conclusion, hip fracture patients who lived alone had higher mortality than those living with a partner, and lower survival relative to the general population.

Word count: 279

Key words (5): population study, hip fracture, cohort study, living-situation, survival 


\section{Introduction}

In recent years, there has been a decline in hip fracture incidence in many Western countries, including in Norway. ${ }^{(1)}$ However, mortality after hip fracture is still high in most parts of the world. Within one year after a hip fracture, 20-30 percent of patients die, ${ }^{(2-6)}$ and excess mortality persists for many years after the fracture. ${ }^{(6-8)}$ The particularly high early mortality has been linked to pre-fracture comorbid conditions such as cardiovascular disease, cancer and dementia, ${ }^{(9,10)}$ factors relating to the treatment (e.g. in-hospital resources, type of surgery and surgical delay), ${ }^{(11,12)}$ and to complications such as infections and delirium. ${ }^{(13,14)}$ The excess mortality after a hip fracture seems to decline after one year in women and after 5 years in men, if genetic factors are taken into account, ${ }^{(15)}$ though additional risk factors may affect long-term mortality, such as inappropriate prescribing of medications, ${ }^{(16)}$ and subsequent fractures. ${ }^{(7,17)}$ The role of social factors has not been extensively studied, but some studies have found increased mortality after hip fracture to be associated with lower income, ${ }^{(14)}$ lower educational attainment, ${ }^{(18)}$ daily smoking, low BMI and other lifestyle-factors. ${ }^{(5,19)}$, and lower amount of perceived social support from friends and family. ${ }^{(20)}$ An association between being unmarried and higher post-hip fracture mortality has also been suggested in women, but results are inconclusive in

men. ${ }^{(21)}{ }^{(20)}$ For unclear reasons, male hip fracture patients have the highest excess mortality, compared to women. ${ }^{(14)}$

In the general population there is a consistent association between lack of social support and mortality, first documented in the 1970 s by Berkman et al., ${ }^{(22)}$ and later summarized in a meta-analysis by HoltLunstad et al. ${ }^{(23)}$ Even in the younger age groups people who live alone have increased risk of dying from cardiovascular events compared to those not living alone. ${ }^{(24,25)}$ Whether a person is living alone or not has been found to predict mortality in community dwelling elderly, ${ }^{(23,26)}$ and it is also a feasible measure which may easily be included in both public health interventions and in clinical settings as an 
indicator of a need for closer follow-up after hip fracture. We aimed to study the influence of living situation (alone or with a partner) on post hip fracture mortality in men and women, according to categories of age and time from hip fracture to death, taking into account possible confounding of other socio-economic- and lifestyle factors. We also aimed to compare the survival of fracture patients according to living situation (alone or with a partner) to the survival rates of the corresponding groups in the general population without a hip fracture.

\section{Materials and Methods}

Study Design and Study population

Statistics Norway conducted in November 2001 a Census where household questionnaires, including questions on living situation ("Family Type") were distributed to the entire Norwegian population. Household members were listed on the questionnaire based on reports from the National Population Register, and each household was asked to add or remove any persons according to their actual habitation status. For this longitudinal cohort study, we included the 2001 Census population who were alive and at risk of hip fracture in the period 1 January 2002 to 31 December 2013, with mortality follow up to 31 October 2014. Only ages 50-79 years at time of fracture were included to reduce misclassification from change in living situation during follow-up due to the increasing proportion being referred to a permanent nursing home residence or losing their partner after the age of 80 . Ages 50-79 years at fracture corresponded to an attained age of 50-92 years at death (maximum of 12 years of follow-up after the hip fracture). We included 1,912,739 fracture-free participants from the 2001 Census for comparison when calculating age-standardized mortality rates and relative survival ( supplementary figure 1). The National Population Register provided data on death and emigration. 
The NOREPOS ${ }^{(27)}$ Hip Fracture Database (NORHip) consists of data on hip fractures treated in Norwegian hospitals from 1 January 1994 to 31 December 2013. Incident hip fractures were identified by taking into account hip fracture diagnosis codes (ICD-9: 820-820.9 and ICD-10 S72.0-S72.2), surgical procedure codes that were characteristic for a primary hip fracture surgery (including surgical procedure codes for hemiarthroplasty occurring without any accompanying reoperation codes), additional diagnosis codes indicating an incident hip fracture, and time between hospitalizations (>3 weeks). Up to two hip fractures in the whole time- period were counted for each person. Fractures occurring from 1994-2007 were retrieved directly from each hospital, whereas fractures from 2008 through 2013 were obtained from the Norwegian Patient Registry. The unique 11-digit personal identification number assigned to every citizen in Norway was used to identify hospitalizations for hip fracture and for all data-linkages. Information on hip fracture definitions, classification, quality assurance, and validation is available online: www.norepos.no/documentation and in Omsland et al (2012). ${ }^{(28)}$

A total of 12,770 men and 22,067 women aged 50-79 years had a first incident hip fracture during 20022013. For those with missing information on Family type, marital status was used as a proxy for living situation $(n=401)$.

Exposure and covariates: Living situation, marital status, education level, number of children and urbanization level

From the 2001 Census we used information collected on Family type (25 categories, described in supplementary material), marital status (9 categories), education (9 categories), and number of children (continuous). Family type identifies practical living situation as it is based on all the individuals reported to live in the same household, rather than on marital status. Hence, married couples who had separate dwellings, e.g. one of them living in an institution and the other at their home, were registered as living apart, whereas non-married cohabiting couples were registered as living together. Family type was 
grouped into a binary variable: living alone (with or without children in the household or elsewhere) versus living with a partner (with or without children in the household or elsewhere). Number of children was categorized as no children, 1 to 2 children, and 3 or more children for descriptive analysis, but included as a continuous variable for adjustment in the regression models. Attained education level was recoded into three categories: Primary (0-9 years), secondary (10-12 years), and tertiary ( $\geq 13$ years). As post hip fracture mortality has been found to vary between urban and rural areas in Norway, ${ }^{(29)}$ and the proportion who live alone or with a partner differed between urban and rural areas, an indicator of urbanization degree in the individual's municipality of residence was included. Urbanization degree was defined on a continuous scale from 0-1, according to the proportion of geographic entities situated less than 50 meters apart in the 2001 Census, 1 being the most urban (as defined by Statistics Norway).

\section{Statistics}

The statistical package Stata 16 (StataCorp, Texas, USA) was used for analysis. Age standardized mortality was calculated per 10,000 person-years, using direct standardization and the average age distribution of the 2001 Census population (including those who later sustained a hip fracture) in 1-year age groups as standard. Median survival time after fracture was estimated with the stci command in Stata. Associations between living situation and mortality were adjusted for age at the Census, education ( 3 groups), urbanization degree (continuous) and number of children (continuous) in flexible parametric survival models (stpm2 command in Stata), which allow non-proportional hazards and enable prediction of time-varying hazard ratios. Hazard ratios (HR) with $95 \%$ confidence intervals (95\% $\mathrm{Cl}$ ) were calculated, using days since hip fracture as observation time. All analyses were done separately by gender. Non-proportional hazards of living situation and age at the 2001 Census were found by interacting these variables with a spline in (log) time and inspecting model fit. The association between living situation and mortality was therefore reported according to four categories of increasing post- 
fracture follow-up time: 0-30 days, 1 month-1 year, $>1-5$ years and $>5-12$ years, in addition to overall HRs for the entire time period. Statistical interactions between living situation and the other covariates (age, education level, urbanization degree, and number of children) were tested. In the models, hazard ratios were allowed to vary over time by including a tvc option for living situation.

\section{Comorbidity}

For administrative reasons, Charlson Comorbidity Index (CCI) was not available for the whole time period of hip fractures (2002-2013), but was explored within a subset of 20,582 individuals with fractures (years 2002-2008) with mortality follow up to 31 Oct. 2014. A modified $\mathrm{CCl}^{(30-32)}$ was used to classify patients according to the severity and the number of comorbid conditions, calculated from additional diagnosis codes recorded during the hospitalization for the hip fracture (see Supplementary Material for an overview of the diagnoses included and the distribution of $\mathrm{CCl}$ by age group). The total $\mathrm{CCl}$ score of a patient was used to classify the patients into three groups: $0=$ no additional diagnosis codes, $1=$ some comorbidity (one additional diagnosis with weight 1 ), $2=$ severe comorbidity (a score of 22). Additional adjustment for $\mathrm{CCl}$ in investigating the association between living situation and mortality was performed, and potential interactions between $\mathrm{CCl}$ score and living situation were tested.

\section{Relative survival}

To compare the survival of hip fracture patients to the expected survival in the general population without a hip fracture, we analysed relative survival over follow-up time after fracture. A relative survival of 1 indicates no excess all-cause mortality of the hip fracture population compared to the expected mortality in the general population, while relative survival values lower than 1 indicate excess mortality in the hip fracture population. Expected mortality was calculated by multiplying the number of person-years in hip fracture patients with the death rate of the general population within strata of 0.5 year age groups (attained age 50-92 years at death), gender, calendar time at death and living situation 
(alone or with a partner). The expected mortality rate within these strata were then merged to the hip fracture population with the same strata characteristics. Differences in excess mortality (i.e., the deviation from expected mortality) were investigated using flexible parametric survival models with the bhazard option, adjusting for age at the 2001 Census, education, urbanization degree and number of children. From these models, relative survival of the hip fracture patients by living situation categories, were predicted over follow-up time (figure 3 ) and at 1 year and 8 years after hip fracture.

\section{Sensitivity analyses}

To assess whether information on marital status would predict post-hip fracture excess mortality equally well as the actual living situation registered in the 2001 Census, living situation (alone or with a partner) was replaced by dichotomous marital status (married/not married, 'not married' including never married, separated, divorced and widowed) in a model adjusting for age, education level and number of children. As those living alone without a partner could potentially be receiving support from their children, we also explored the association between post hip-fracture mortality and a living situation variable with 3 categories (presented in Supplementary Material): Living with a partner with or without children in the household or elsewhere, living alone but having children in the household or elsewhere, and living alone having no children. In a separate analysis we also excluded those who had children living in their household.

Ideally, living situation should have been collected at the time of fracture. To take into account the potential misclassification caused by changes in living situation between the 2001 Census and time of hip fracture, we performed a sensitivity analysis restricting the fracture inclusion period to hip fractures occurring within four years after the 2001 Census (through 2005, chosen to retain statistical power). In addition, we performed an analysis excluding those who had a second hip fracture in the follow-up 
period ( $10 \%$ of all hip fracture patients). Lastly, we included the population $>79$ years in a separate analysis.

\section{Ethics}

This study was approved by the Norwegian Data Inspectorate, the Directorate of Health, Statistics Norway, the Regional Committee for Medical and Health Research Ethics and the Norwegian Institute of Public Health.

\section{Results}

A total of 34,837 individuals $(12,770$ men and 22,067 women) aged 50-79 years at time of fracture, suffered a hip fracture during the period $2002-2013$. Of these $40.5 \%$ were living alone without a partner (11.6\% were living alone and had no children). Table 1 shows the characteristics of the hip fracture population. Men living alone fractured at a lower age than those living with a partner (mean 68.2 versus 69.6 years); while women living alone fractured at a higher age than those living with a partner (mean 71.8 versus 70.2 years). Additionally, among the patients living alone a higher proportion had completed $<12$ years of education, a higher percentage were living in urban areas, and those living alone had on average fewer children. A comparison of the hip fracture population to the characteristics of the general population aged 50-79 years at the 2001 Census is shown in supplementary table 1.

\section{All-cause mortality}

Median survival time after fracture was shorter in both men ( 4.9 years versus 6.9 years) and women (7.3 versus 10. 3 years for women) living alone compared to those living with a partner. Figure 1 shows agestandardized mortality rates (with $95 \% \mathrm{Cl}$ ) in the general population and in those who have had a hip fracture, by living situation (alone or with a partner) and gender. Hip fracture patients were 50-79 years 
at the time of fracture. In general, individuals living alone had a higher mortality compared to individuals living with a partner, both in the general population and among hip fracture patients (figure 1).

An overall $37 \%$ higher post hip fracture mortality was found in male hip fracture patients who lived alone compared with the male hip fracture patients who lived with a partner: $\mathrm{HR}=1.37,95 \% \mathrm{Cl}: 1.29$, 1.44, adjusting for age at Census, education level, urbanization degree and number of children. In women with a hip fracture, the corresponding mortality was $23 \%$ higher: $\mathrm{HR}=1.23,95 \% \mathrm{Cl}: 1.18,1.28$. Table 2 shows the association between living situation and post-hip fracture mortality, according to time after fracture. In both genders, there was a significant association between living situation and postfracture mortality at all follow-up times, and the associations were, in general stronger with long-term follow-up.

Age at fracture

Figure 2 shows the time-varying hazard ratios (HR) for post-hip fracture mortality in those living alone versus those living with a partner over follow-up time for men (a) and women (b), stratified on three groups of age at fracture. In men, the relative difference in mortality (HR) was largest in the youngest age group (50-59 years) over the entire follow-up period, and increased toward the end of follow up time (at 12.8 years, predicted $\mathrm{HR}=3.29(95 \% \mathrm{Cl}: 2.25,6.49))$. In women, the age group 50-59 years had the largest relative difference in mortality the first day post-fracture ( $H R=2.19,95 \% \mathrm{Cl}: 1.41,9.07)$, but the hazard ratio also peaked at 2.9 years post-fracture (predicted $\mathrm{HR}=1.96,95 \% \mathrm{Cl}: 1.41,2.81$ ).

\section{Comorbidity}

When adjusting for comorbidity level in the subset of those who fractured up to 2008 , the association was unchanged at most follow-up times (supplementary table 2). There was a significant interaction between living situation and comorbidity level in both genders $(p<0.004)$, with a stronger relative risk of 
dying after hip fracture in those living alone versus those living with a partner in the group of no registered comorbidity (supplementary table 3).

\section{Survival relative to the non-fracture background population}

Figure 3 shows the estimated relative survival, according to gender and living situation, and adjusted for age at Census, education level, urbanization degree and number of children, over post-fracture time. The overall survival was lower in hip fracture patients relative to the general population $(<1)$, and decreased steadily over the entire follow-up period. Differences in relative survival between the groups (alone vs. living with a partner) increased with post-fracture time until 8 years after fracture.

When predicting relative survival at age 70 years (and with other covariates set to their mean level) 82.3 $\%$ of men living alone had survived 1-year post-fracture, relative to the general population of men of the same age living alone, whereas in the group of men living with a partner the relative survival was $83.4 \%$. Predicted relative survival at 8 years post-fracture, was $43.4 \%$ in men living alone, and $50.8 \%$ in men living with a partner. The corresponding relative survivals in women living alone were $89.2 \%$ at 1 year after hip fracture $(89.8 \%$ in those living with a partner), and $61.1 \%$ at 8 years after hip fracture $(67.0 \%$ in those living with a partner).

\section{Sensitivity analyses}

With the exception of 30-days mortality, women who were living alone and having no children had the overall highest hazard ratio, compared to women living with a partner (supplementary table 4). This was also the case for long-term mortality in men (supplementary table 4). When excluding those with children in the household from the analysis (separate sensitivity analysis), the association between living situation and post-hip fracture mortality was somewhat attenuated in men: $\mathrm{HR}=1.32$ (95\% Cl: $1.25,1.40)$ vs. 1.37 in the main analysis, but unchanged in women. 
Marital status (married vs. not married) was highly correlated with living situation (with partner vs. alone) $(\mathrm{rho}=0.81)$, and there were only minor changes in the association with post-hip fracture mortality when replacing living situation with marital status (results not shown). In analyses restricted to fractures occurring 2002-2005, i.e. closer in time to the registration of living situation in the 2001 Census, the associations between living situation and long-term post hip fracture mortality became stronger: HR in men 5-12 years post fracture increased from 1.59 in the main analysis (Table 2) to 1.68 (supplementary table 5 ). In women, the association with 1-5 years post hip fracture mortality became stronger, HR increasing from 1.29 in the main analysis (Table 2) to HR=1.39 (supplementary table 5). Only minor changes were found in the association when excluding those that experienced a second fracture in the follow-up period (results not shown). When including the population $>79$ years the overall estimates were attenuated: HR men (living alone versus with a partner): 1.15 (95\% Cl: 1.11, 1.18); HR women (living alone versus with a partner): $1.11(95 \% \mathrm{Cl}: 1.08,1.13)$ (estimates by post-fracture time in supplementary table 6).

\section{Discussion}

In this cohort of 34,837 Norwegian hip fracture patients aged 50-79 years at time of fracture, we found a higher post-hip fracture mortality in both men and women living alone, as opposed to those living with a partner. The association was independent of age, education level, number of children and degree of urbanization. The increased relative risk (HR) of dying in those who lived alone was more evident in younger fracture patients, in men, and in those with no registered comorbid diagnoses at the hip fracture hospitalization, and it increased with time since fracture. When comparing survival in hip fracture patients to the general population, the lowest survival was found among men living alone, whereas the highest survival was among women living with a partner. 
Despite the extensive research on excess mortality after hip fracture, little attention has been given to the role of social factors, in particular social support after hip fracture. We were able to find only two previous studies ${ }^{(20,33)}$ on the role of social contact /social support on post-hip fracture mortality. AlegreLopez et al ${ }^{(33)}$ examined predictors associated with mortality and limited functional ability after discharge from hospital and up to 1 year after hip fracture in a cohort of 218 patients $\geq 50$ years of age. Pre-fracture living situation (alone vs. in the company of others) was not found to be associated with 1year mortality. ${ }^{(33)}$ On the contrary, Mortimore et al, who included 674 community residents aged 65 years and older with hip fracture, found that patients who did not see or speak (both telephone and direct personal contact) with family members two weeks prior to the fracture were more than twice as likely to die within 2 years after fracture, compared to participants who had contact with family members on a daily basis. This is in accordance with results from the current study, and with other studies on social support and mortality in the general population, where the increased was found to be comparable to the risk from smoking and surpassing risk factors such as obesity and lack of physical activity. ${ }^{(23)}$

\section{Interpretation of results}

The lower survival in hip fracture patients living alone relative to the general population indicates that the consequences of a hip fracture may be greater for those living alone versus those living with a partner. In this current study of Norwegian hip fracture patients (with a mean age at fracture of approximately 70 years) around $40 \%$ of patients were living alone. Whether a person is living alone is not a good proxy for loneliness, but a higher degree of social isolation has been found in the general population of older adults living alone. ${ }^{(34,35)}$ Having social relationships has been linked to better immune functioning and to lower immune mediated inflammatory processes over time and can be 
positive in all parts of life. ${ }^{(27)}$ Social support may also have an important "buffering effect" against stress during illness or trauma, such as when experiencing a hip fracture. ${ }^{(33,34,36)}$

The association between living situation and post-fracture mortality in men became stronger with longer time after the hip fracture. The same pattern, although weaker was found in women. As factors related to care, follow-up and rehabilitation after the hip fracture influence survival, social support is expected to be of great importance, putting those living alone after the fracture at greater risk. For older adults, physical function in daily life is a predictor of mortality, and a higher level of social support may indicate more assistance in carrying out everyday tasks and activities. ${ }^{(37)}$ In a scoping review, Auais et al found that both a higher level of social contact and socioeconomic status had beneficial effects on physical recovery after hip fracture. ${ }^{(38)}$ For hip fracture patients living with a partner, social support may imply better adherence to medications, which is important for long-term survival. ${ }^{(17,39)}$ Better nutrition may also play a role, as difficulty in preparing meals after a hip fracture has been found to predict 1-year mortality, and the prevalence of malnutrition in older patients with hip fracture is higher than in other community-dwelling older adults. ${ }^{(40)}$ An adequate nutritional status is characterized by prevention of weight loss and maintaining a healthy $\mathrm{BMI}$, and a study from our research group found $\mathrm{BMI}$ to be an important risk factor for mortality after hip fracture. ${ }^{(19)}$

High mortality after hip fracture has been linked to pre-fracture co-morbid conditions, in particular malignancy, cardiovascular disease and pulmonary disease. ${ }^{(9,10,41)}$ Factors such as delay of surgery is often due to patients' anticoagulant medication regulation and comorbidities optimization. ${ }^{(42)}$ With poor health condition at admittance, surgery will often have to be postponed, and longer waiting time to surgery has been shown to lead to higher excess short-term mortality after hip fracture. ${ }^{(12,41,43)}$ Patients experiencing a fracture in their home may more often have a delay in admission if they live alone and are socially isolated, leading to poorer health condition at admittance. Nevertheless, when 
taking into account the comorbidity level at admittance in the current study, the overall association (HR) did not change. This was in accordance with a register study from Denmark, where Vestergaard et al found that excess mortality could be mainly attributed to complications to the fracture event, and less to pre-fracture co-morbid conditions. ${ }^{(14)}$

Keeping in mind that older men ( $>75$ years) have been found to have the highest absolute mortality after hip fracture, ${ }^{(6,11,21,44)}$ a higher relative mortality was found in younger male hip fracture patients (50-59 years) living alone compared those living with a partner in the current study. Although a diverse group, unmarried Norwegian men are reported to have a higher alcohol intake and receive less social support compared to those who are married. ${ }^{(45)}$ In the Cohort of Norway study, men younger than 60 years who reported frequent drinking had substantially higher risk of hip fracture compared to moderate drinkers, indicating that lifestyle factors such as alcohol intake may matter. ${ }^{(46)} \mathrm{A}$ high alcohol intake may also be associated with a higher degree of comorbidity, ${ }^{(47)}$ and in the current study the association between living situation and mortality in the youngest male hip fracture patients (50-59 years) was somewhat attenuated when adjusting for comorbidity level. Still, there may be several underlying reasons for the relatively higher mortality in the group living alone, and some of these may also be underlying causes of living alone. More studies are therefore needed to explore this higher relative post-fracture mortality.

Having children has been found to reduce mortality after hospitalization for any cause in adults over 70 years in Sweden. ${ }^{(48)}$ We found that the association between living situation and post- fracture mortality was not as strong for those living alone who had children as for those who lived alone and did not have children, indicating that the support from children may matter to a certain extent.

Measures of social support have also been shown to be associated with socioeconomic status, i.e. individuals in higher socioeconomic groups are more likely to be married, have more friends and report 
higher levels of social support, and high socioeconomic status has been found to predict lower post-hip fracture mortality. ${ }^{(18,24)}$ In the current study, the association between living situation and mortality in hip fracture patients was only slightly attenuated when including education level, a common proxy of socioeconomic status.

Post-hip fracture mortality has been reported to be higher in urban than in rural areas of Norway after the first 30 days post-fracture, which could possibly be related to lower quality of follow-up care in urban areas. ${ }^{(29)}$ In addition, urban dwellers are observed to have less social contact and fewer friends they can rely on for help than people living in rural areas. ${ }^{(49)}$ The association (HR) between living situation and post-fracture mortality did not change when adjusting for degree of urbanization in the current study, indicating that there may be other underlying mechanisms for this association.

\section{Strengths and limitations}

The strengths include the large population and the prospective design, which made it possible to consider associations in a young group of hip fracture patients over 12.8 years of follow-up. We also had information on actual living situation, not only marital status, although marital status was found to be a good proxy for living situation in this population. We had complete capture of hip fracture-data from all hospitals in Norway, death and emigration provided by National Registers, and we were able to compare our estimates to the general population from a National Census.

There are some limitations. Living situation was classified based on the information obtained from the 2001 Census, and it was measured at one time point. For a proportion of unknown magnitude, it would have changed between Census time and the fracture event, and between the fracture and time of death or end of follow-up. The degree of misclassification would be 
expected to increase with elapsed time after the 2001 Census. When limiting the analyses to fractures occurring the first 4 years after the Census, the associations became somewhat stronger. We defined living alone as not living with a partner. However, some patients defined as living alone may still have other supportive family members, such as siblings, living in their household, which we were not able to capture. Additionally, we excluded the population $\geq 80$ years at fracture due to substantial portion of patients at this age moving to nursing homes after the fracture; however, we cannot rule out that this also pertains to some of the younger patients. Comorbidity (Charlson Comorbidity Index, $\mathrm{CCl}$ ) in the fracture patients was calculated from registered diagnoses at the time of admittance to hospital for the fracture. This may be a gross underestimate of the actual comorbidity in this population, as only diagnoses deemed relevant for the health assessment during the hospital stay are usually registered, and some diagnoses that are strongly associated with survival were not included, such as psychiatric illness (except dementia). ${ }^{(33)}$ This suggests that some hip fracture patients with no apparent comorbidity in our data may not necessarily be considered as healthy. It is also possible that patients living alone approach the health system less often than those living with a partner, and therefore have fewer comorbid diagnoses registered at admittance. This could potentially explain the strong association between living situation and post hip fracture mortality in the nocomorbidity group. Lastly, our study is based on data from registers and Census, which means that information on lifestyle factors (for example smoking and alcohol use) and clinical risk factors, such as complications to the surgical procedure, were not available. We therefore cannot rule out the potential for residual confounding of our results, or the possibility of collider stratification bias if living situation was strongly associated with hip fracture risk. 


\section{Conclusion}

Despite a decline in the age-adjusted incidence of hip fracture over the last decades in Norway, the mortality after hip fracture is still high. Living alone is linked to higher mortality in the general population, and we have shown that the risk of mortality also is higher in hip fracture patients living alone. The relatively higher post-hip fracture mortality was most prominent in men, in the younger patients and in those without any hospital registered comorbid conditions. Currently, all hip fracture patients in Norway are being followed up by home nursing care, or admitted to a nursing home/rehabilitation unit after discharge from the hospital, regardless of their living situation. However, our study shows that there may be an overlooked need for an even closer follow-up for a longer post-fracture period in patients who are living alone. A patient's living situation is attainable information that tailored fracture liaison services may need to consider it to make sure the patient stays compliant with prescribed medications and a bone- healthy diet. In addition, further emphasis should be put on creating supportive, social communities for senior citizens. These efforts may prove to become even be more important in the future, as populations grow older.

\section{Figure Legends}

Figure 1. Age standardized rates (and 95\% Confidence Interval) of mortality per 10,000 person years in the general population and in the hip fracture population (50-79 years) by living situation (living with a partner/living alone). Directly standardized rates using the age distribution in the entire population (including hip fracture patients) 50-92 years at death as 
standard. Population and Housing Census 2001 and NORHip database 2002-2013, with

mortality follow up from the National Population Register to 31 Oct. 2014.

Figure 2. Predicted hazard ratio of the association between living situation (alone versus with a partner) and post hip fracture mortality over follow-up time and according to age at fracture. Population and Housing Census 2001 and NORHip database 2002-2013, with mortality follow up from the National Population Register to 31 Oct. 2014.

Figure 3. Predicted survival in hip fracture patients relative to the non-fracture background population stratified on living situation and gender. Population and Housing Census 2001 and NORHip database 2002-2013, with mortality follow up from the National Population Register to 31 Oct. 2014.

\section{Acknowledgements}

The study was partially supported by the Norwegian Research Council. Staff at the Norwegian Institute of Public Health and Statistics Norway are acknowledged for transferring and encrypting the hip fracture data and for the linkage to the other data sources. NOREPOS (The NORwegian EPidemiologic Osteoporosis Studies) (www.norepos.no) is a collaboration between epidemiologic osteoporosis studies, which are sub-studies within large population-based surveys in four districts of Norway (Troms $\varnothing$, NordTrøndelag, Hordaland, Oslo). We also want to acknowledge the other members of NOREPOS Research Group.

Disclaimer. Data from the Norwegian Patient Registry has been used in this publication. The interpretation and reporting of these data are the sole responsibility of the authors, and no endorsement by the Norwegian Directorate of Health is intended nor should be inferred.

Author roles: Data collection and validation: AJS, TKO, KH, HEM, Data analysis: CD, TKO, SMS and HS. Data interpretation: all authors. Drafting manuscript: CD. Revising manuscript content: all authors. Approving final version of manuscript: all authors. CD and TKO take responsibility for the integrity of the data analysis.

\section{References}


1. Sogaard AJ, Holvik K, Meyer HE, Tell GS, Gjesdal CG, Emaus N, et al. Continued decline in hip fracture incidence in Norway: a NOREPOS study. Osteoporosis international : a journal established as result of cooperation between the European Foundation for Osteoporosis and the National Osteoporosis Foundation of the USA. Jul 2016;27(7):2217-22. Epub 2016/02/24.

2. Haentjens P, Magaziner J, Colon-Emeric CS, Vanderschueren D, Milisen K, Velkeniers B, et al. Meta-analysis: excess mortality after hip fracture among older women and men. Annals of internal medicine. Mar 16 2010;152(6):380-90. Epub 2010/03/17.

3. Haleem S, Lutchman L, Mayahi R, Grice JE, Parker MJ. Mortality following hip fracture: trends and geographical variations over the last 40 years. Injury. Oct 2008;39(10):1157-63. Epub 2008/07/26.

4. Johnell O, Kanis JA, Oden A, Sernbo I, Redlund-Johnell I, Petterson C, et al. Mortality after osteoporotic fractures. Osteoporosis international : a journal established as result of cooperation between the European Foundation for Osteoporosis and the National Osteoporosis Foundation of the USA. Jan 2004;15(1):38-42. Epub 2003/11/01.

5. Meyer HE, Tverdal A, Falch JA, Pedersen JI. Factors associated with mortality after hip fracture. Osteoporosis international : a journal established as result of cooperation between the European Foundation for Osteoporosis and the National Osteoporosis Foundation of the USA. 2000;11(3):228-32. Epub 2000/05/29.

6. Omsland TK, Emaus N, Tell GS, Magnus JH, Ahmed LA, Holvik K, et al. Mortality following the first hip fracture in Norwegian women and men (1999-2008). A NOREPOS study. Bone. Jun 2014;63:81-6. Epub 2014/03/13.

7. Abrahamsen B, van Staa T, Ariely R, Olson M, Cooper C. Excess mortality following hip fracture: a systematic epidemiological review. Osteoporosis international : a journal established as result of cooperation between the European Foundation for Osteoporosis and the National Osteoporosis Foundation of the USA. Oct 2009;20(10):1633-50. Epub 2009/05/08.

8. Kanis JA, Oden A, Johnell O, De Laet C, Jonsson B, Oglesby AK. The components of excess mortality after hip fracture. Bone. May 2003;32(5):468-73. Epub 2003/05/20.

9. Holvik K, Ranhoff AH, Martinsen MI, Solheim LF. Predictors of mortality in older hip fracture inpatients admitted to an orthogeriatric unit in oslo, norway. Journal of aging and health. Dec 2010;22(8):1114-31. Epub 2010/10/01.

10. Lunde A, Tell GS, Pedersen AB, Scheike TH, Apalset EM, Ehrenstein V, et al. The Role of Comorbidity in Mortality After Hip Fracture: A Nationwide Norwegian Study of 38,126 Women With Hip Fracture Matched to a General-Population Comparison Cohort. Am J Epidemiol. Feb 1 2019;188(2):398-407. Epub 2018/11/09.

11. Dailiana Z, Papakostidou I, Varitimidis S, Michalitsis S, Veloni A, Malizos K. Surgical treatment of hip fractures: factors influencing mortality. Hippokratia. Jul 2013;17(3):252-7. Epub 2014/01/29.

12. Sheehan KJ, Sobolev B, Guy P. Mortality by Timing of Hip Fracture Surgery: Factors and Relationships at Play. The Journal of bone and joint surgery American volume. Oct 18 2017;99(20):e106. Epub 2017/10/19.

13. Uriz-Otano F, Uriz-Otano JI, Malafarina V. Factors associated with short-term functional recovery in elderly people with a hip fracture. Influence of cognitive impairment. Journal of the American Medical Directors Association. Mar 2015;16(3):215-20. Epub 2014/12/03.

14. Vestergaard P, Rejnmark L, Mosekilde L. Increased mortality in patients with a hip fractureeffect of pre-morbid conditions and post-fracture complications. Osteoporosis international : a journal established as result of cooperation between the European Foundation for Osteoporosis 
and the National Osteoporosis Foundation of the USA. Dec 2007;18(12):1583-93. Epub 2007/06/15.

15. Michaëlsson K, Nordström P, Nordström A, Garmo H, Byberg L, Pedersen NL, et al. Impact of hip fracture on mortality: a cohort study in hip fracture discordant identical twins. J Bone Miner Res. Feb 2014;29(2):424-31. Epub 2013/07/04.

16. Gosch M, Wortz M, Nicholas JA, Doshi HK, Kammerlander C, Lechleitner M. Inappropriate prescribing as a predictor for long-term mortality after hip fracture. Gerontology. 2014;60(2):114-22. Epub 2013/11/20.

17. Diamantopoulos AP, Hoff M, Hochberg M, Haugeberg G. Predictors of short- and long-term mortality in males and females with hip fracture - a prospective observational cohort study. PloS one. 2013;8(10):e78169. Epub 2013/11/10.

18. Omsland TK, Eisman JA, Naess O, Center JR, Gjesdal CG, Tell GS, et al. Educational Inequalities in Post-Hip Fracture Mortality: A NOREPOS Study. J Bone Miner Res. Dec 2015;30(12):2221-8. Epub 2015/06/19.

19. Solbakken SM, Meyer HE, Stigum H, Sogaard AJ, Holvik K, Magnus JH, et al. Excess mortality following hip fracture: impact of self-perceived health, smoking, and body mass index. A NOREPOS study. Osteoporosis international : a journal established as result of cooperation between the European Foundation for Osteoporosis and the National Osteoporosis Foundation of the USA. Mar 2017;28(3):881-7. Epub 2016/10/08.

20. Mortimore E, Haselow D, Dolan M, Hawkes WG, Langenberg P, Zimmerman S, et al. Amount of social contact and hip fracture mortality. J Am Geriatr Soc. Jun 2008;56(6):1069-74. Epub 2008/04/16.

21. Roberts SE, Goldacre MJ. Time trends and demography of mortality after fractured neck of femur in an English population, 1968-98: database study. Bmj. Oct 04 2003;327(7418):771-5. Epub 2003/10/04.

22. Berkman LF, Syme SL. Social networks, host resistance, and mortality: a nine-year follow-up study of Alameda County residents. Am J Epidemiol. Feb 1979;109(2):186-204. Epub 1979/02/01.

23. Holt-Lunstad J, Smith TB, Layton JB. Social relationships and mortality risk: a meta-analytic review. PLoS medicine. Jul 27 2010;7(7):e1000316. Epub 2010/07/30.

24. Stringhini S, Berkman L, Dugravot A, Ferrie JE, Marmot M, Kivimaki M, et al. Socioeconomic status, structural and functional measures of social support, and mortality: The British Whitehall II Cohort Study, 1985-2009. Am J Epidemiol. Jun 15 2012;175(12):1275-83. Epub 2012/04/27.

25. Udell JA, Steg PG, Scirica BM, Smith SC, Jr., Ohman EM, Eagle KA, et al. Living alone and cardiovascular risk in outpatients at risk of or with atherothrombosis. Archives of internal medicine. Jul 23 2012;172(14):1086-95. Epub 2012/06/20.

26. Tabue Teguo M, Simo-Tabue N, Stoykova R, Meillon C, Cogne M, Amieva H, et al. Feelings of Loneliness and Living Alone as Predictors of Mortality in the Elderly: The PAQUID Study. Psychosomatic medicine. Oct 2016;78(8):904-9. Epub 2016/10/18.

27. Sogaard AJ, Meyer HE, Emaus N, Grimnes G, Gjesdal CG, Forsmo S, et al. Cohort profile: Norwegian Epidemiologic Osteoporosis Studies (NOREPOS). Scand J Public Health. Dec 2014;42(8):804-13. Epub 2014/10/04.

28. Omsland TK, Holvik K, Meyer HE, Center JR, Emaus N, Tell GS, et al. Hip fractures in Norway 1999-2008: time trends in total incidence and second hip fracture rates. A NOREPOS study. Eur J Epidemiol. 6/30/2012 2012.

29. Solbakken SM, Magnus JH, Meyer HE, Dahl C, Stigum H, Søgaard AJ, et al. Urban-rural differences in hip fracture mortality. A nationwide NOREPOS study. JBMR Plus.0(ja):e10236. 
30. Charlson ME, Pompei P, Ales KL, MacKenzie CR. A new method of classifying prognostic comorbidity in longitudinal studies: development and validation. J Chronic Dis. 1987;40(5):37383. Epub 1987/01/01.

31. Quan H, Sundararajan V, Halfon P, Fong A, Burnand B, Luthi JC, et al. Coding algorithms for defining comorbidities in ICD-9-CM and ICD-10 administrative data. Medical care. Nov 2005;43(11):1130-9. Epub 2005/10/15.

32. Stagg V. CHARLSON: Stata module to calculate Charlson index of comorbidity. Statistical Software Components S456719: Boston College Department of Economics; 2006.

33. Alegre-Lopez J, Cordero-Guevara J, Alonso-Valdivielso JL, Fernandez-Melon J. Factors associated with mortality and functional disability after hip fracture: an inception cohort study.

Osteoporosis international : a journal established as result of cooperation between the European Foundation for Osteoporosis and the National Osteoporosis Foundation of the USA. Jul 2005;16(7):729-36. Epub 2004/11/05.

34. Bucholz EM, Krumholz HM. Loneliness and living alone: what are we really measuring? Archives of internal medicine. Jul 23 2012;172(14):1084-5. Epub 2012/06/20.

35. Perissinotto CM, Covinsky KE. Living alone, socially isolated or lonely--what are we measuring? Journal of general internal medicine. Nov 2014;29(11):1429-31. Epub 2014/08/06.

36. Olstad R, Sexton H, Søgaard AJ. The Finnmark Study. A prospective population study of the social support buffer hypothesis, specific stressors and mental distress. Social Psychiatry and Psychiatric Epidemiology. 2001/12/01 2001;36(12):582-9.

37. Perissinotto CM, Stijacic Cenzer I, Covinsky KE. Loneliness in older persons: a predictor of functional decline and death. Archives of internal medicine. Jul 23 2012;172(14):1078-83. Epub 2012/06/20.

38. Auais M, Al-Zoubi F, Matheson A, Brown K, Magaziner J, French SD. Understanding the role of social factors in recovery after hip fractures: A structured scoping review. Health Soc Care Community. Aug 25 2019. Epub 2019/08/26.

39. Peng J, Liu Y, Chen L, Peng K, Xu Z, Zhang D, et al. Bisphosphonates can prevent recurrent hip fracture and reduce the mortality in osteoporotic patient with hip fracture: A meta-analysis. Pakistan journal of medical sciences. Mar-Apr 2016;32(2):499-504. Epub 2016/05/18.

40. Malafarina V, Reginster JY, Cabrerizo S, Bruyere O, Kanis JA, Martinez JA, et al. Nutritional Status and Nutritional Treatment Are Related to Outcomes and Mortality in Older Adults with Hip Fracture. Nutrients. Apr 30 2018;10(5). Epub 2018/05/02.

41. Chang W, Lv H, Feng C, Yuwen P, Wei N, Chen W, et al. Preventable risk factors of mortality after hip fracture surgery: Systematic review and meta-analysis. International journal of surgery (London, England). Apr 2018;52:320-8. Epub 2018/03/14.

42. Makridis KG, Badras LS, Badras SL, Karachalios TS. Searching for the 'winner' hip fracture patient: the effect of modifiable and non-modifiable factors on clinical outcomes following hip fracture surgery. Hip Int. Sep 23 2019:1120700019878814. Epub 2019/09/25.

43. Klestil T, Roder C, Stotter C, Winkler B, Nehrer S, Lutz M, et al. Impact of timing of surgery in elderly hip fracture patients: a systematic review and meta-analysis. Sci Rep. Sep 17 2018;8(1):13933. Epub 2018/09/19.

44. Kannegaard PN, van der Mark S, Eiken P, Abrahamsen B. Excess mortality in men compared with women following a hip fracture. National analysis of comedications, comorbidity and survival. Age Ageing. Mar 2010;39(2):203-9. Epub 2010/01/16.

45. Nordfjaern T, Brunborg GS. Associations Between Human Values and Alcohol Consumption Among Norwegians in the Second Half of Life. Subst Use Misuse. 2015;50(10):1284-93. Epub 2015/01/21. 
46. Sogaard AJ, Ranhoff AH, Meyer HE, Omsland TK, Nystad W, Tell GS, et al. The association between alcohol consumption and risk of hip fracture differs by age and gender in Cohort of Norway: a NOREPOS study. Osteoporosis international : a journal established as result of cooperation between the European Foundation for Osteoporosis and the National Osteoporosis Foundation of the USA. Nov 2018;29(11):2457-67. Epub 2018/07/15.

47. O'Keefe JH, Bhatti SK, Bajwa A, DiNicolantonio JJ, Lavie CJ. Alcohol and cardiovascular health: the dose makes the poison...or the remedy. Mayo Clin Proc. Mar 2014;89(3):382-93. Epub 2014/03/04.

48. Meyer AC, Brooke HL, Modig K. The role of children and their socioeconomic resources for the risk of hospitalisation and mortality - a nationwide register-based study of the total Swedish population over the age 70. BMC geriatrics. Apr 23 2019;19(1):114. Epub 2019/04/25.

49. Blekesaune A, Haugen MS. Ageing in Norwegian Rural and Urban Communities. 2018;10(2):232. 


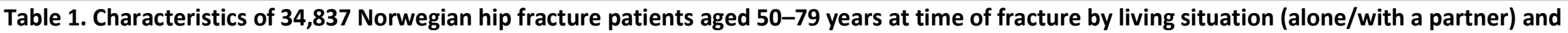
gender. The NOREPOS Hip Fracture Database (2002-2013) with mortality follow-up from the National Population Register to 31 Oct. 2014.

\begin{tabular}{|c|c|c|c|c|c|}
\hline & & \multicolumn{2}{|c|}{ Men $(n=12,770)$} & \multicolumn{2}{|c|}{ Women $(n=22,067)$} \\
\hline & & $\begin{array}{l}\text { Living alone } \\
(36.6 \%)\end{array}$ & $\begin{array}{l}\text { Living with a partner } \\
\text { (63.4\%) }\end{array}$ & $\begin{array}{l}\text { Living alone } \\
(43.0 \%)\end{array}$ & $\begin{array}{l}\text { Living with a partner } \\
(57.0 \%)\end{array}$ \\
\hline Number of hip fractures & & 4,734 & 8,199 & 9,573 & 12,696 \\
\hline Number of person-years & & 18,564 & 35,117 & 47,409 & 63,196 \\
\hline Number of deaths & & 2,667 & 3,805 & 4,724 & 4,413 \\
\hline \multicolumn{2}{|c|}{ Number of deaths $<1$ year after fracture } & 937 & 1,360 & 1,218 & 1,281 \\
\hline \multicolumn{2}{|c|}{ Mean age at time of hip fracture in years $\left(S D^{a}\right)^{b}$} & $68.2(8.2)$ & $69.6(7.9)$ & $71.8(7.1)$ & $70.2(7.4)$ \\
\hline \multicolumn{2}{|l|}{ Mean number of children $\left(S D^{a}\right)^{c}$} & $1.3(1.5)$ & $2.3(1.3)$ & $1.9(1.5)$ & $2.4(1.4)$ \\
\hline \multirow[t]{3}{*}{ Education level, $\mathrm{N}(\%)^{\mathrm{c}}$} & $<12$ years & $2,048(43.3)$ & $2,541(31.1)$ & $4,503(47.0)$ & $5,193(40.9)$ \\
\hline & 12 years & $2,146(45.3)$ & $4,180(51.0)$ & $4,018(42.0)$ & $5,938(46.7)$ \\
\hline & $>12$ years & $461(9.7)$ & $1,413(17.2)$ & $940(9.8)$ & $1,503(11.8)$ \\
\hline \multirow[t]{3}{*}{ Urbanization category, $\mathrm{N}(\%)^{\mathrm{C}}$} & Rural & $353(7.5)$ & $596(7.3)$ & $588(6.1)$ & $901(7.1)$ \\
\hline & Semirural & $1,086(22.9)$ & $2,060(25.1)$ & $1,970(20.6)$ & $3,224(25.4)$ \\
\hline & Urban & $3,295(69.6)$ & $5,544(67.6)$ & $7,015(73.3)$ & $8,571(67.5)$ \\
\hline
\end{tabular}




\begin{tabular}{|c|c|c|c|c|c|}
\hline Marital status, $\mathrm{N}(\%)^{\mathrm{c}}$ & Married & $90(1.9)$ & $7,524(91.8)$ & $129(1.35)$ & $11,951(94.1)$ \\
\hline & Previously married & $2,710(57.1)$ & $452(5.5)$ & $7,951(83.1)$ & $572(4.5)$ \\
\hline & Never married & $1,943(41.0)$ & $224(2.7)$ & $1,493(15.6)$ & $173(1.4)$ \\
\hline Fractures occuring in winter, $\mathrm{N}(\%)$ & October-March & $2,622(55.3)$ & $4,812(58.7)$ & $5,289(55.3)$ & $7,137(56.3)$ \\
\hline \multirow[t]{3}{*}{ Charlson comorbidity level, $N(\%)^{d}$} & 0 & $1452(52.5)$ & $2,397(52.5)$ & $3,573(56.6)$ & $4,255(61.4)$ \\
\hline & 1 & $714(25.9)$ & $1,096(23.4)$ & $1,676(26.5)$ & $1,679(24.2)$ \\
\hline & 2 & $599(21.7)$ & $1,075(23.5)$ & $1,067(16.9)$ & 999(14.4) \\
\hline
\end{tabular}

All comparisons significant at $p<0.05$, except fractures occurring in winter (women)

Minor variations in numbers due to missing in some covariates

a Standard deviation

${ }^{\mathrm{b}}$ Range: $\mathbf{5 0 - 7 9}$ years

c From the 2001 Housing and Population Census (Statistics Norway)

${ }^{d}$ From the NORHip database. Subset of hip fracture patients 2002-2008: 7,333 men; 13, 249 women.

Table 2. Hazard ratios with $95 \%$ confidence intervals ${ }^{a}$ for mortality after hip fracture in persons living alone vs. living with a partner (reference), according to time after hip fracture. 34,837 patients 50-79 years at the time of fracture. The NOREPOS Hip Fracture Database (2002-2013) with mortality follow-up from the National Population Register to 31 Oct. 2014.

\begin{tabular}{|c|c|c|c|c|}
\hline & $\begin{array}{l}\text { Number of } \\
\text { deaths }\end{array}$ & $\begin{array}{l}\text { Adjusted for age at } \\
\text { Census }^{b}\end{array}$ & $\begin{array}{l}\text { Adjusted for age at Census }{ }^{b} \text {, } \\
\text { education level }\end{array}$ & $\begin{array}{l}\text { Adjusted for age at Census }{ }^{b} \text {, education level }{ }^{b} \\
\text { urbanization degree }^{b} \text { and number of children }\end{array}$ \\
\hline Men & & & & \\
\hline
\end{tabular}




\begin{tabular}{|c|c|c|c|c|}
\hline $0-30$ days post fracture & 650 & $1.30(1.11,1.51)^{* *}$ & $1.25(1.06,1.46)^{* *}$ & $1.25(1.05,1.48)^{* *}$ \\
\hline 1-12 months post-fracture & 1,647 & $\begin{array}{l}1.28(1.16 \\
1.41)^{* * *}\end{array}$ & $1.27(1.15,1.40)^{* * *}$ & $1.28(1.16,1.43)^{* * *}$ \\
\hline$>1-5$ years post-fracture & 2,854 & $\begin{array}{l}1.42(1.32 \\
1.53)^{* * *}\end{array}$ & $1.39(1.29,1.50)^{* * *}$ & $1.36(1.26 .1 .48)^{* * *}$ \\
\hline \multicolumn{5}{|l|}{ Women } \\
\hline $0-30$ days post fracture & 601 & $1.14(0.97,1.34)$ & $1.13(0.96,1.33)$ & $1.13(0.96,1.33)$ \\
\hline 1-12 months post-fracture & 1,898 & $\begin{array}{l}1.18(1.07 \\
1.29)^{* * *}\end{array}$ & $1.17(1.07,1.28)^{* *}$ & $1.15(1.05,1.26)^{* *}$ \\
\hline$>1-5$ years post-fracture & 4,002 & $\begin{array}{l}1.34(1.25 \\
1.42) * * *\end{array}$ & $1.32(1.24,1.41)^{* * *}$ & $1.29(1.21,1.37)^{* * *}$ \\
\hline$>5-12$ years post fracture & 2,636 & $\begin{array}{l}1.26(1.17 \\
1.36)^{* * *}\end{array}$ & $1.24(1.15,1.34)^{* * *}$ & $1.22(1.13,1.32)^{* * *}$ \\
\hline \multicolumn{5}{|c|}{$\begin{array}{l}{ }^{*} p<0.05,{ }^{*} p<0.01, * * * p<0.001 \\
\text { a } \text { Flexible parametric survival analysis } \\
\text { b From the } 2001 \text { Housing and Population Census (Statistics Norway) }\end{array}$} \\
\hline
\end{tabular}


Figure 1

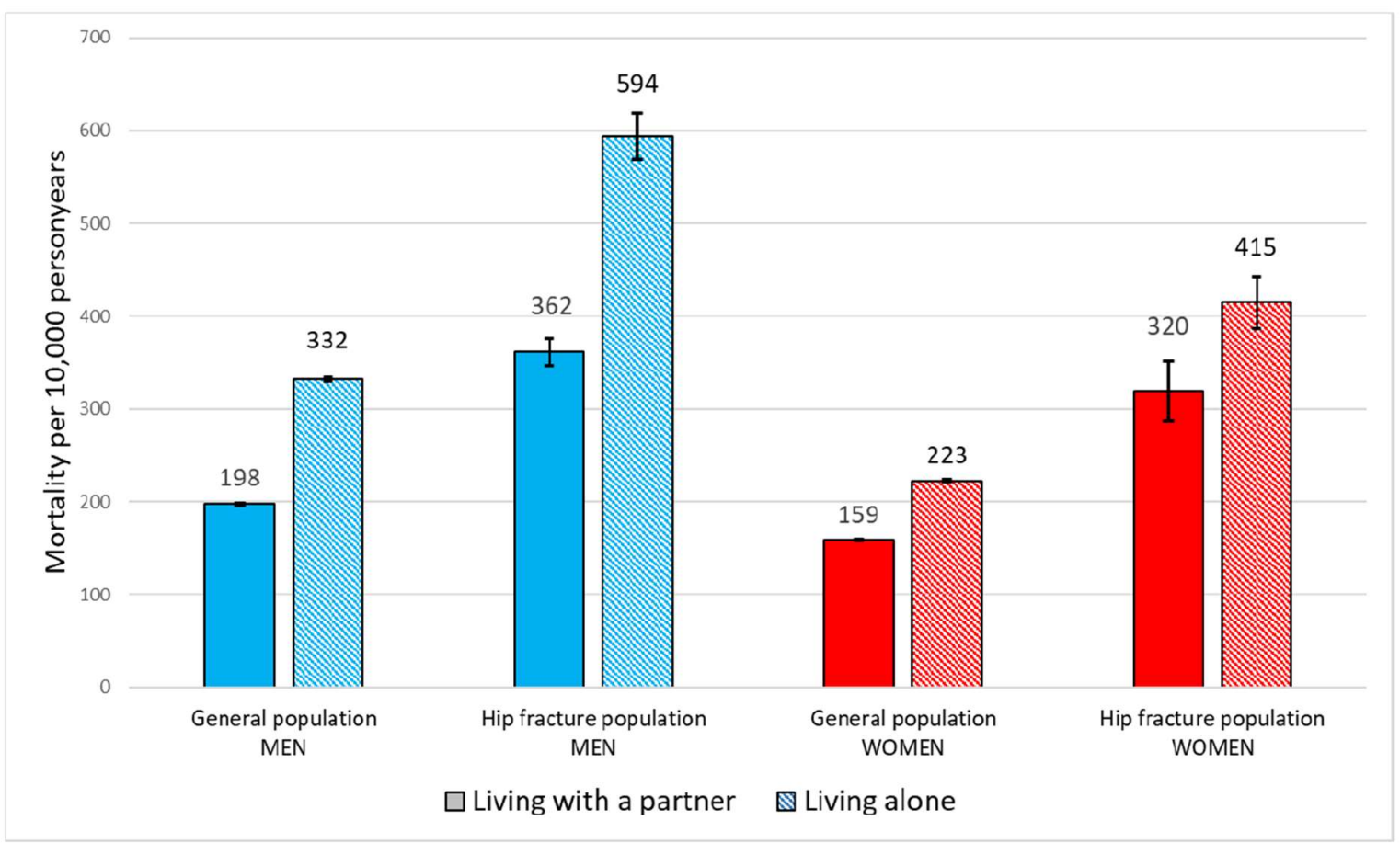


Figure 2
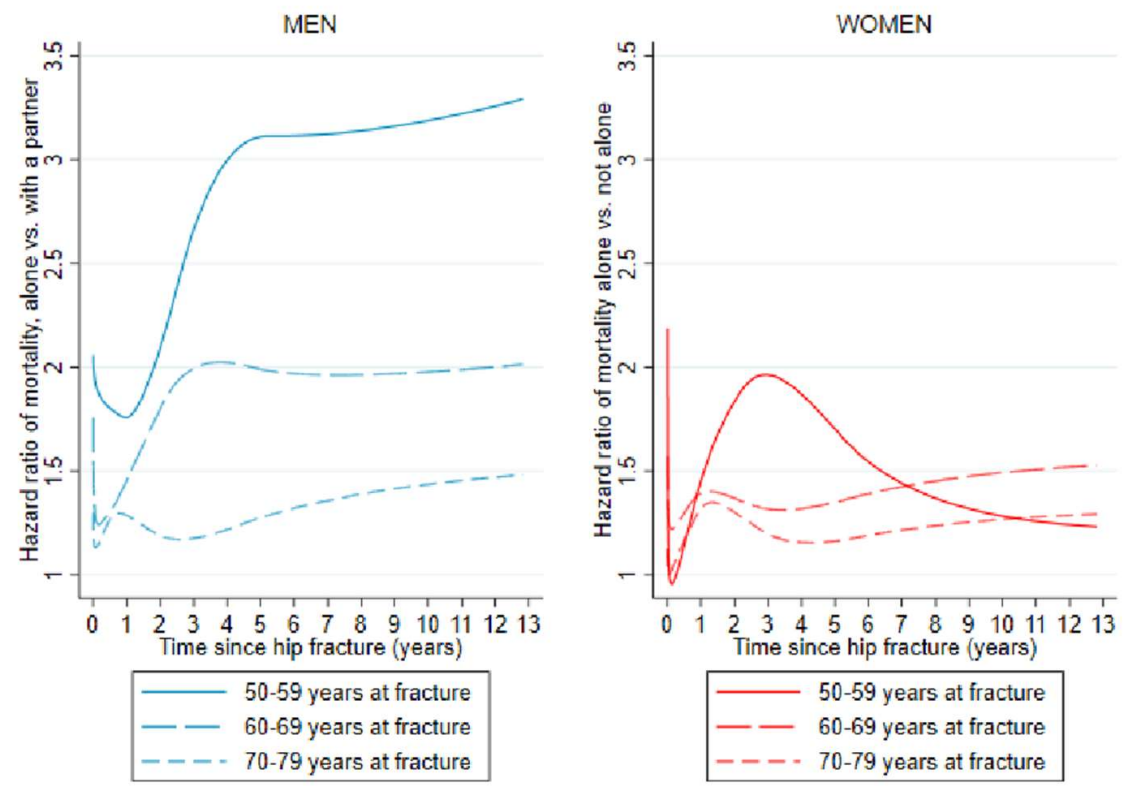
Figure 3

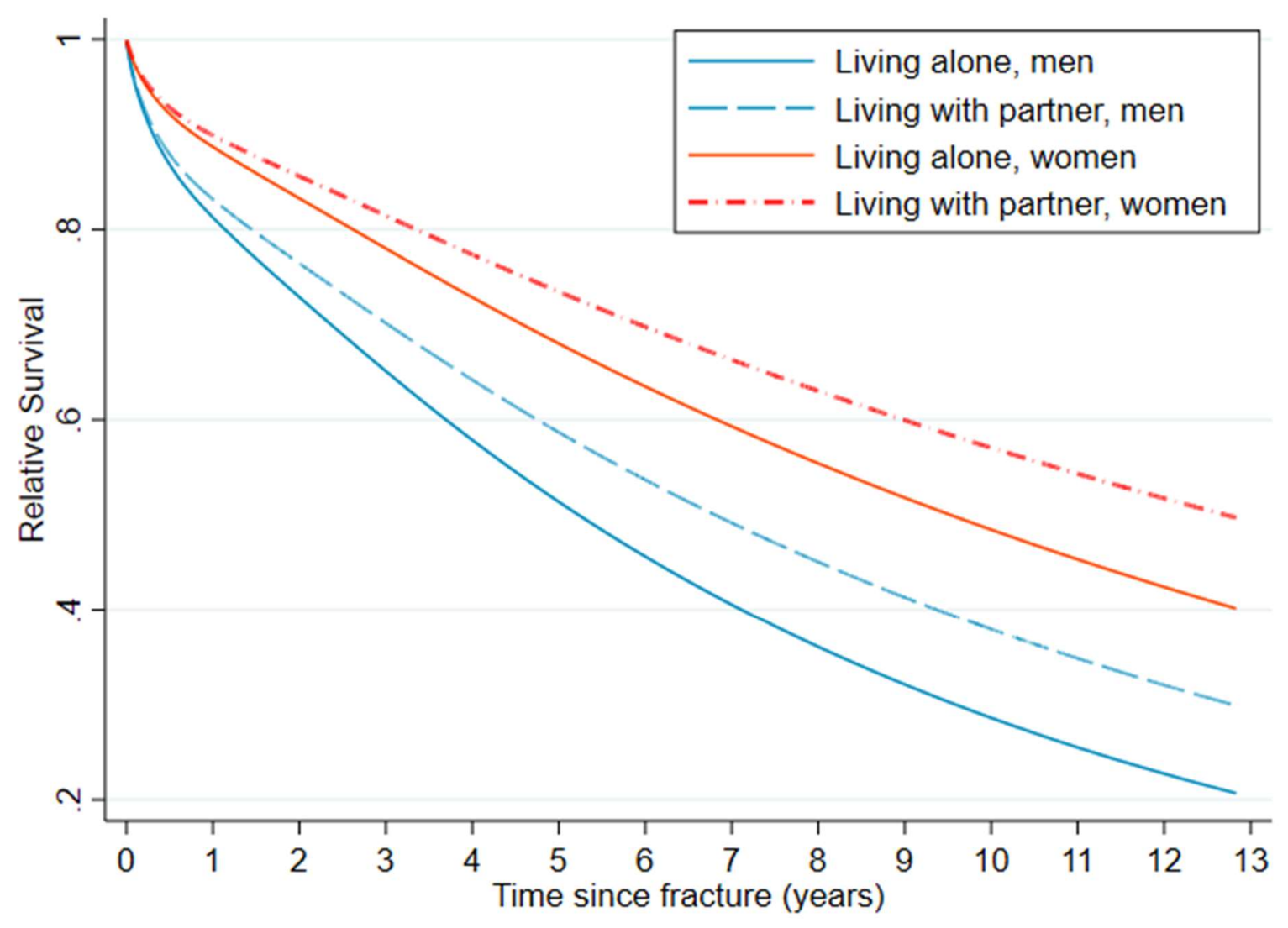


Increased mortality in hip fracture patients living alone. A NOREPOS study

\section{SUPPLEMENTARY MATERIAL}

\section{Methods}

Supplementary figure 1. Flow chart depicting the number of participants with and without hip fracture included in the study

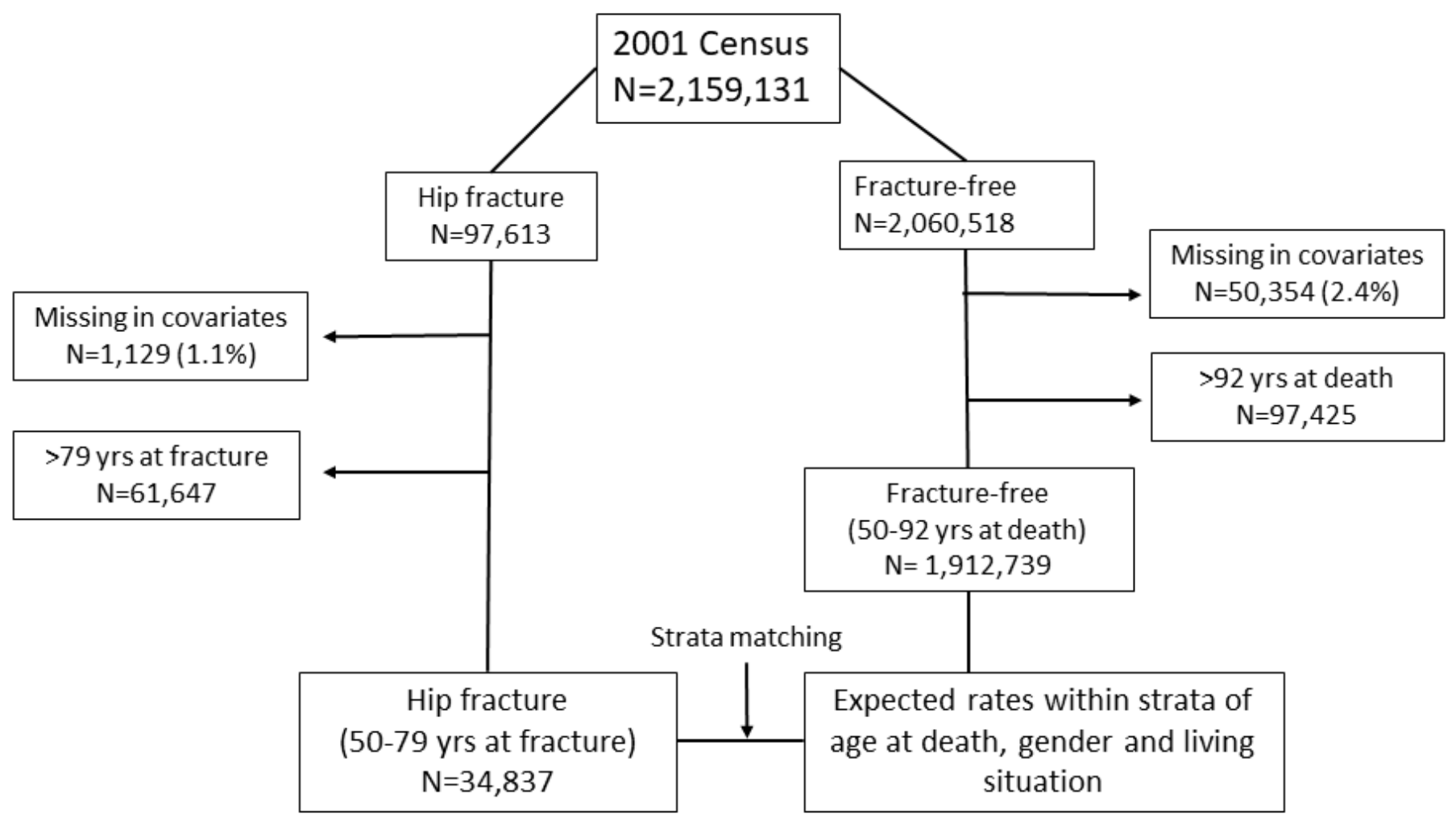




\section{SUPPLEMENTARY MATERIAL}

\section{Variable Family type (categories)}

1. Single person family, person $<30$ years of age

2. Single person family, person $30-44$ years of age

3. Single person family, person $45-66$ years of age

4. Single person family, person $>67$ years of age

5. Married couple without children, oldest person $<30$ years of age

6. Married couple without children, oldest person 30-44 years of age

7. Married couple without children, oldest person $45-66$ years of age

8. Married couple without children, oldest person $>67$ years of age

9. Married couple with small children (youngest child 0-5 years of age)

10. Married couple with older children (youngest child 6-17 years of age)

11. Married couple with adult children (youngest child $\geq 18$ years of age)

12. Cohabiting couple without children, oldest person $<30$ years of age

13. Cohabiting couple without children, oldest person 30-44 years of age

14. Cohabiting couple without children, oldest person $45-66$ years of age

15. Cohabiting couple without children, oldest person $>67$ years of age

16. Cohabiting couple with small children (youngest child 0-5 years of age)

17. Cohabiting couple with older children (youngest child 6-17 years of age)

18. Cohabiting couple with adult children (youngest child $\geq 18$ years of age)

19. Mother with small children (youngest child $0-5$ years of age)

20. Mother with older children (youngest child 6-17 years of age)

21. Mother with adult children (youngest child $\geq 18$ years of age)

22. Father with small children (youngest child $0-5$ years of age)

23. Father with older children (youngest child 6-17 years of age)

24. Father with adult children (youngest child $\geq 18$ years of age)

25. Other family types (e.g. several families in one household)

Main exposure: Living situation (binary)

\begin{tabular}{|c|c|}
\hline Categories & Original variable categories \\
\hline Living alone & Family type category $1-4,19-24$ \\
\hline Living with a partner & Family type category 5-18 \\
\hline Missing (1.2\%) ${ }^{\mathrm{a}}$ & Family type category $25+$ missing Family type \\
\hline
\end{tabular}


Increased mortality in hip fracture patients living alone. A NOREPOS study

\section{SUPPLEMENTARY MATERIAL}

Sensitivity analysis: Living situation (3 groups)

\begin{tabular}{|lll|}
\hline Categories & $\begin{array}{l}\text { Original variable (1) } \\
\text { categories }\end{array}$ & $\begin{array}{l}\text { Original variable (2) } \\
\text { categories }\end{array}$ \\
\hline $\begin{array}{l}\text { Living alone } \\
\begin{array}{l}\text { Living alone, but have } \\
\text { children }\end{array}\end{array}$ & $\begin{array}{l}\text { Family type category 1-4 } \\
\text { Fiving with a partner }\end{array}$ & $\begin{array}{l}\text { No registered children } \\
19-24\end{array}$ \\
$\begin{array}{l}\text { Missing } \\
\text { Family type category 5-18 }\end{array}$ & $\begin{array}{l}\text { Family type category 25 and } \\
\text { missing in Family type }\end{array}$ & Any number of children \\
& & \\
\hline
\end{tabular}

Diagnoses included in the Charlson Comorbidity index (CCl):

\begin{tabular}{l} 
AMI (Acute Myocardial Infarction) \\
CHF (Congestive Heart Failure) \\
PVD (Peripheral Vascular Disease) \\
CVD (Cerebrovascular Disease) \\
Dementia \\
COPD (Chronic Obstructive Pulmonary) \\
Rheumatoid Disease \\
Peptic Ulcer Disease \\
Mild LD (Liver Disease) \\
Diabetes \\
Diabetes + Complications \\
HP/PAPL (Hemiplegia or Paraplegia) \\
RD (Renal Disease) \\
Cancer \\
Moderate/Severe LD (Liver Disease) \\
Metastatic Cancer \\
AIDS (Aquired Immune Deficiency Syndrome) \\
\hline
\end{tabular}

Charlson Comorbidity index (CCl) by age group (hip fracture patients only):

\begin{tabular}{|c|c|c|c|}
\hline & $\mathrm{CCl}=0^{\mathrm{a}}$ & $\mathrm{CCl}=1^{\mathrm{b}}$ & $\mathrm{CCl}=2^{\mathrm{C}}$ \\
\hline $50-59$ years, $N(\%)$ & $1,790(72.8)$ & $384(15.6)$ & $286(11.6)$ \\
\hline 60-69 years, $N(\%)$ & $3,129(63.4)$ & 1,015 (20.7) & $754(15.4)$ \\
\hline $70-79$ years, $N(\%)$ & $6,745(51.1)$ & $3,764(28.5)$ & $2,702(20.5)$ \\
\hline \multicolumn{4}{|c|}{$\begin{array}{l}\text { a no additional diagnosis code } \\
\text { b some comorbidity (one additional diagnosis with weight } 1 \text { ) } \\
\text { c severe comorbidity (a score of } \geq 2 \text { ) }\end{array}$} \\
\hline
\end{tabular}


Increased mortality in hip fracture patients living alone. A NOREPOS study

\section{SUPPLEMENTARY MATERIAL}

\section{Results}

\begin{tabular}{|c|c|c|c|}
\hline \multicolumn{4}{|c|}{$\begin{array}{l}\text { Supplementary table } 1 \text {. Comparison of } 595,495 \text { men and } 628,723 \text { women with and } \\
\text { without hip fracture in the } 2001 \text { Population and Housing Census (Statistics Norway), } \\
\text { ages } 50-79 \text { years at time of the Census. Hip fracture registration from the NORHip } \\
\text { database (2002-2013), Norwegian Epidemiologic Osteoporosis Studies (NOREPOS) }\end{array}$} \\
\hline Characteristic & & $\begin{array}{l}\text { Hip fracture }\left(1^{\text {st }}\right) \\
N=60,654\end{array}$ & $\begin{array}{l}\text { General population } \\
N=1,163,564\end{array}$ \\
\hline $\begin{array}{l}\text { Number of deceased 2002- } \\
2014(\%)\end{array}$ & & $32,307(53.3)$ & $265,932(22.9)$ \\
\hline $\begin{array}{l}\text { Age at census } \\
\text { mean (SD) }\end{array}$ & & $70.0(7.7)$ & $61.7(8.5)$ \\
\hline \multirow[t]{2}{*}{ Gender N (\%) } & Men & $19,919(32.8)$ & $575,576(49.5)$ \\
\hline & Women & $40,735(67.7)$ & $587,988(50.5)$ \\
\hline \multirow[t]{2}{*}{ Living situation $\mathbf{N}(\%)$} & $\begin{array}{l}\text { Living with } \\
\text { a partner }\end{array}$ & $33,548(55.3)$ & $830,578(71.4)$ \\
\hline & Living alone & $27,106(44.7)$ & $332,986(28.6)$ \\
\hline \multirow[t]{3}{*}{ Marital status N (\%) } & Married & $332,553(53.4)$ & $785,500(67.5)$ \\
\hline & $\begin{array}{l}\text { Never } \\
\text { married }\end{array}$ & $5,205(8.6)$ & $86,463(7.4)$ \\
\hline & $\begin{array}{l}\text { Previously } \\
\text { married }\end{array}$ & $22,896(37.8)$ & $291,601(25.1)$ \\
\hline \multirow[t]{3}{*}{ Number of children $\mathbf{N}(\%)$} & 0 & $11,565(19.1)$ & $178,075(15.3)$ \\
\hline & 1 & $8,624(14.2)$ & $132,496(11.4)$ \\
\hline & $\geq 2$ & $40,315(66.5)$ & $841,719(72.3)$ \\
\hline \multirow[t]{3}{*}{ Education level $\mathbf{N}(\%)$} & $<12$ years & $27,905(46.0)$ & $365,745(31.4)$ \\
\hline & 12years & $25,897(42.7)$ & $567,911(48.8)$ \\
\hline & $>12$ years & $6,310(10.4)$ & $217,096(18.7)$ \\
\hline \multirow[t]{3}{*}{ Urbanization category $\mathbf{N}(\%)$} & Rural & $4,374(7.2)$ & $84,085(7.2)$ \\
\hline & Semirural & 14,479 (23.9) & $274,995(23.6)$ \\
\hline & Urban & 41,801 (68.9) & $1804,484(69.1)$ \\
\hline
\end{tabular}


Increased mortality in hip fracture patients living alone. A NOREPOS study

\section{SUPPLEMENTARY MATERIAL}

Supplementary table 2. Association (Hazard ratio, 95\% Confidence Interval) between living situation and post-fracture mortality in 20,582 hip fracture patients 50-79 years at the time of fracture. Living alone versus living with a partner (reference). Subset of NORHip database (2002-2008) with mortality follow-up from the National Population Register to 31 Oct. 2014.

\begin{tabular}{|c|c|c|}
\hline & $\begin{array}{l}\text { Adjusted for age at Census, education } \\
\text { level, urbanization degree and number } \\
\text { of children }\end{array}$ & $\begin{array}{l}\text { Additional adjustment for comorbidity } \\
\text { level }\end{array}$ \\
\hline \multicolumn{3}{|l|}{ Men } \\
\hline $\begin{array}{l}0-30 \text { days post } \\
\text { fracture }\end{array}$ & $1.25(1.01,1.56)^{*}$ & $1.27(1.02,1.58)^{*}$ \\
\hline $\begin{array}{l}\text { 1-12 months post- } \\
\text { fracture }\end{array}$ & $1.34(1.17,1.53)^{* * *}$ & $1.33(1.16,1.52)^{* * *}$ \\
\hline $\begin{array}{l}>1-5 \text { years post- } \\
\text { fracture }\end{array}$ & $1.45(1.31,1.60)^{* * *}$ & $1.44(1.30,1.59)^{* * *}$ \\
\hline $\begin{array}{l}>5-12 \text { years post } \\
\text { fracture }\end{array}$ & $1.60(1.29,1.98)^{* * *}$ & $1.58(1.28,1.97)^{* * *}$ \\
\hline \multicolumn{3}{|l|}{ Women } \\
\hline $\begin{array}{l}0-30 \text { days post } \\
\text { fracture }\end{array}$ & $1.20(0.97,1.49)$ & $1.14(0.91,1.42)$ \\
\hline $\begin{array}{l}\text { 1-12 months post- } \\
\text { fracture }\end{array}$ & $1.10(0.98,1.23)$ & $1.05(0.94,1.18)$ \\
\hline $\begin{array}{l}>1-5 \text { years post- } \\
\text { fracture }\end{array}$ & $1.36(1.25,1.48)^{* * *}$ & $1.34(1.24,1.46)^{* * *}$ \\
\hline $\begin{array}{l}>5-12 \text { years post } \\
\text { fracture }\end{array}$ & $1.19(1.03,1.38)^{*}$ & $1.19(1.02,1.37)^{*}$ \\
\hline \multicolumn{3}{|c|}{${ }^{*} p<0.05, * * * p<0.001$} \\
\hline
\end{tabular}




\section{SUPPLEMENTARY MATERIAL}

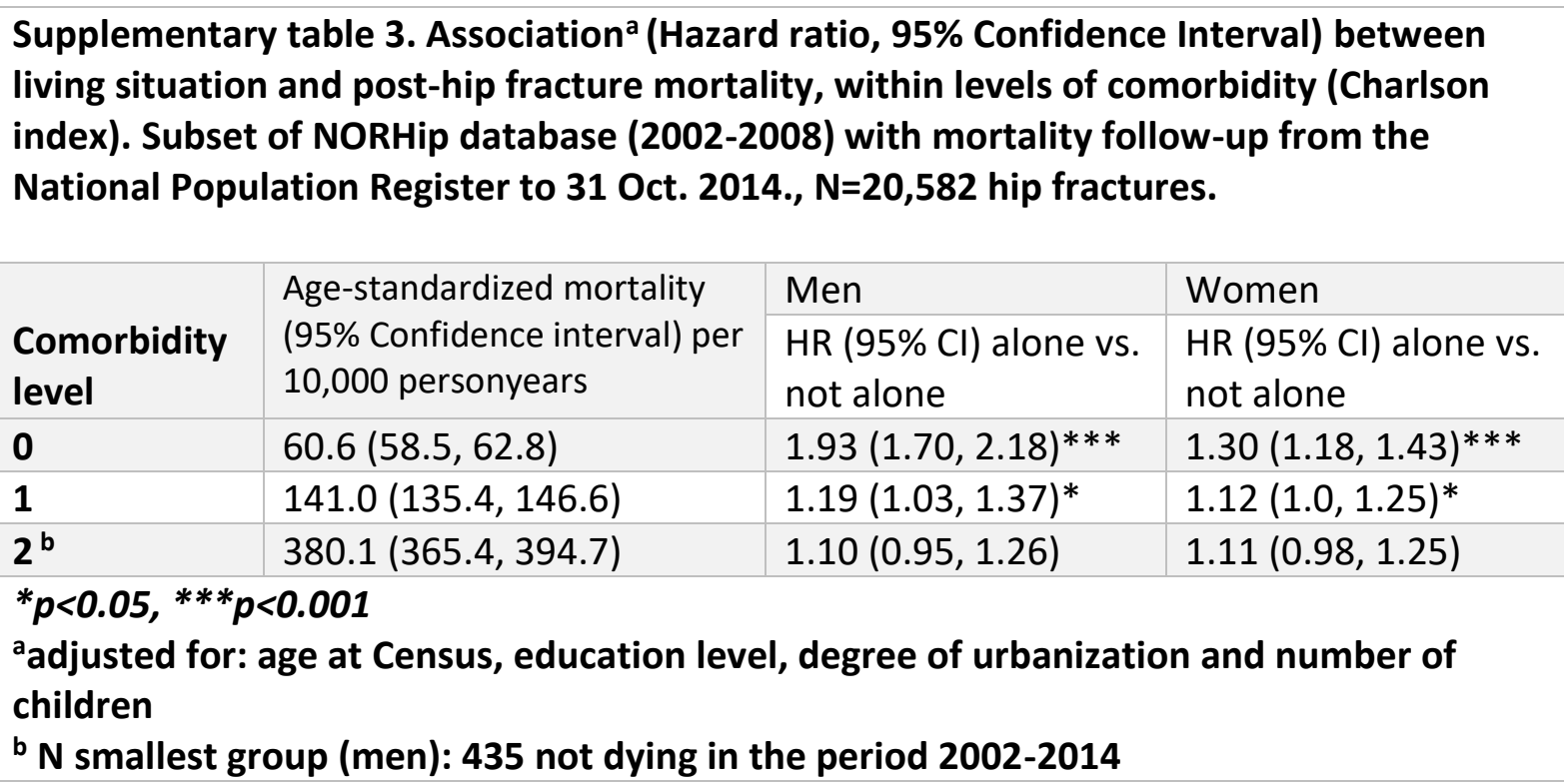




\section{SUPPLEMENTARY MATERIAL}

Supplementary table 4. Association ${ }^{a}$ (Hazard ratio, 95\% Confidence Interval) between living situation in 3 categories and post-hip fracture mortality at different follow-up times. 34,837 men and women 50-79 years at fracture, NORHip database (2002-2013) with mortality follow-up from the National Population Register to 31 Oct. 2014.

\begin{tabular}{|c|c|c|c|c|}
\hline & $0-30$ days & $1-12$ months & $>1-5$ years & $5-12$ years \\
\hline \multicolumn{5}{|l|}{ Men } \\
\hline $\begin{array}{l}\text { Living with a } \\
\text { partner (children } \\
\text { or no children }{ }^{\text {b }}\end{array}$ & Reference & Reference & Reference & Reference \\
\hline $\begin{array}{l}\text { Living alone (have } \\
\text { children }^{\text {b) }}\end{array}$ & $\begin{array}{l}1.25(1.03 \\
1.52)^{*}\end{array}$ & $\begin{array}{l}1.28(1.13 \\
1.44)^{* * *}\end{array}$ & $\begin{array}{l}1.40(1.28 \\
1.54)^{* * *}\end{array}$ & $\begin{array}{l}1.53(1.33 \\
1.76)^{* * *}\end{array}$ \\
\hline $\begin{array}{l}\text { Living alone (have } \\
\text { no children }{ }^{\text {b }} \text { ) }\end{array}$ & $\begin{array}{l}1.24(1.0 \\
1.53)\end{array}$ & $\begin{array}{l}1.18(1.03 \\
1.36)^{*}\end{array}$ & $\begin{array}{l}1.31(1.18 \\
1.45)^{* * *}\end{array}$ & $\begin{array}{l}1.59(1.37 \\
1.84)^{* * *}\end{array}$ \\
\hline \multicolumn{5}{|l|}{ Women } \\
\hline $\begin{array}{l}\text { Living with a } \\
\text { partner (children } \\
\text { or no children }{ }^{b} \text { ) }\end{array}$ & Reference & Reference & Reference & Reference \\
\hline $\begin{array}{l}\text { Living alone (have } \\
\text { children }^{\text {b) }}\end{array}$ & $\begin{array}{l}1.14(0.96, \\
1.36)\end{array}$ & $\begin{array}{l}1.13(1.02, \\
1.25)^{*}\end{array}$ & $\begin{array}{l}1.27(1.18 \\
1.35)^{* * *}\end{array}$ & $\begin{array}{l}1.19(1.09 \\
1.29)^{* * *}\end{array}$ \\
\hline $\begin{array}{l}\text { Living alone (have } \\
\text { no children }{ }^{\text {b }}\end{array}$ & $\begin{array}{l}1.00(0.75, \\
1.35)\end{array}$ & $\begin{array}{l}1.23(1.05 \\
1.43)^{* *}\end{array}$ & $\begin{array}{l}1.35(1.21 \\
1.49)^{* * *}\end{array}$ & $\begin{array}{l}1.31(1.15 \\
1.48)^{* * *}\end{array}$ \\
\hline
\end{tabular}




\section{SUPPLEMENTARY MATERIAL}

Supplementary table 5. Association ${ }^{a}$ (Hazard ratio, $95 \%$ Confidence Interval) between living situation and post-hip fracture mortality at different follow-up times. Sensitivity analysis restricted to 11,984 men and women 50-79 years at fracture with hip fracture from 1 January 2002- 31 December 2005 (NORHip database) with mortality follow-up from the National Population Register to 31 Oct. 2014.

\begin{tabular}{|c|c|c|c|c|}
\hline & $0-30$ days & 1- 12 months & $>1-5$ years & $5-12$ years \\
\hline \multicolumn{5}{|l|}{ Men } \\
\hline $\begin{array}{l}\text { Living with a } \\
\text { partner }\end{array}$ & Reference & Reference & Reference & Reference \\
\hline Living alone & $\begin{array}{l}1.25(0.96, \\
1.65)\end{array}$ & $\begin{array}{l}1.25(1.04, \\
1.49)^{*}\end{array}$ & $\begin{array}{l}1.40(1.24 \\
1.58)^{* * *}\end{array}$ & $\begin{array}{l}1.68(1.46 \\
1.92)^{* * *}\end{array}$ \\
\hline \multicolumn{5}{|l|}{ Women } \\
\hline $\begin{array}{l}\text { Living with a } \\
\text { partner }\end{array}$ & Reference & Reference & Reference & Reference \\
\hline Living alone & $\begin{array}{l}1.23(0.92 \\
1.64)\end{array}$ & $\begin{array}{l}1.06(0.90, \\
1.23)\end{array}$ & $\begin{array}{l}1.39(1.26 \\
1.54)^{* * *}\end{array}$ & $\begin{array}{l}1.21(1.10 \\
1.32)^{* * *}\end{array}$ \\
\hline \multicolumn{5}{|c|}{$\begin{array}{l}{ }^{*} p<0.05,{ }^{*} p<0.01 * * *, p<0.001 \\
\text { a adjusted for age at Census, education level and urbanization degree and number of } \\
\text { children }\end{array}$} \\
\hline
\end{tabular}


Increased mortality in hip fracture patients living alone. A NOREPOS study

\section{SUPPLEMENTARY MATERIAL}

Supplementary table 6 . Hazard ratios with $95 \%$ confidence intervals ${ }^{a, b}$ for mortality after hip fracture in persons living alone vs. living with a partner (reference), according to time after hip fracture. 95,887 patients 50-107 years of age. The NOREPOS Hip Fracture Database (2002-2013) with mortality follow-up from the National Population Register to 31 Oct. 2014.

\begin{tabular}{|c|c|c|c|}
\hline & $\begin{array}{l}\text { Number of deaths } \\
\text { (50-107 years of age) }\end{array}$ & $\begin{array}{l}\mathrm{HR}(95 \% \mathrm{Cl}) \text {, ages } 50- \\
107 \text { years at fracture }\end{array}$ & $\begin{array}{l}\mathrm{HR}(95 \% \mathrm{Cl}) \text {, ages } 50-70 \text { at } \\
\text { fracture }^{\mathrm{c}}\end{array}$ \\
\hline \multicolumn{4}{|l|}{ Men } \\
\hline $0-30$ days post fracture & 3,383 & $1.01(0.94,1.09)$ & $1.25(1.05,1.48)^{* *}$ \\
\hline $\begin{array}{l}\text { 1-12 months post- } \\
\text { fracture }\end{array}$ & 6,060 & $1.09(1.03,1.15)^{* *}$ & $1.28(1.16,1.43)^{* * *}$ \\
\hline$>1-5$ years post-fracture & 8,129 & $1.13(1.08,1.19)^{* * *}$ & $1.36(1.26 .1 .48)^{* * *}$ \\
\hline$>5-12$ years post fracture & 2,476 & $1.21(1.11,1.32)^{* * *}$ & $1.59(1.41,1.78)^{* * *}$ \\
\hline \multicolumn{4}{|l|}{ Women } \\
\hline $0-30$ days post fracture & 4,166 & $1.09(1.01,1.17)^{*}$ & $1.13(0.96,1.33)$ \\
\hline $\begin{array}{l}\text { 1-12 months post- } \\
\text { fracture }\end{array}$ & 10,068 & $1.08(1.03,1.13)^{* *}$ & $1.15(1.05,1.26)^{* *}$ \\
\hline$>1-5$ years post-fracture & 19,741 & $1.10(1.06,1.13)^{* * *}$ & $1.29(1.21,1.37)^{* * *}$ \\
\hline$>5-12$ years post fracture & 8,433 & $1.14(1.08,1.19)^{* * *}$ & $1.22(1.13,1.32)^{* * *}$ \\
\hline \multicolumn{4}{|c|}{$\begin{array}{l}{ }^{*} p<0.05,{ }^{* *} p<0.01,{ }^{* *} p<0.001 \\
\text { a Flexible parametric survival analysis } \\
\text { b Adjusted for age at Census, education level, urbanization degree and number of children } \\
\text { c Main analysis for comparison }\end{array}$} \\
\hline
\end{tabular}

